\title{
Commentary: Surgical resection has limited role in primary cardiac lymphoma
}

\author{
Hon Chi Suen, MBBS, ${ }^{a}$ and \\ Michael K. Y. Hsin, FRCS CTh ${ }^{\mathrm{b}}$
}

Primary cardiac lymphoma (PCL) is a very rare malignancy, which is typically of a non-Hodgkin's type. It accounts for $1 \%$ of the primary cardiac tumors and $0.5 \%$ of extranodal lymphomas. ${ }^{1}$ The publications on PCL consist of case reports or small single-center series, and there are currently no clear guidelines on the management of PCL.

In this issue of the Journal, Yin and colleagues ${ }^{2}$ from Boston and Houston made an important contribution to the literature by studying 43 years of Surveillance, Epidemiology, and End Results (SEER) data regarding PCL. They identified 184 cases of PCL, of which $80 \%$ were diffuse large B-cell lymphoma, and 65\% in early stages. Twenty percent of patients received no treatment at all, and $73 \%$ of patients received chemotherapy. Fourteen percent of the cohort underwent surgery, including excisional biopsy in just under one-third of surgical patients. Local resection or debulking was performed in $10 \%$ of all patients, and this study did not find overall survival in this group, whereas chemotherapy was independently associated with improved survival. Advanced age and stage were independently associated with worse survival. Four patients had combined chemotherapy, surgery (local resection or debulking), and radiotherapy, although the impact of combination treatment on survival was not reported.

The authors recommended that surgical intervention, with the exception of biopsy, should only be offered to PCL patients who are (1) hemodynamically unstable, (2) unable to tolerate chemotherapy, or (3) require palliative

\footnotetext{
From the ${ }^{\mathrm{a}}$ Hong Kong Sanitorium and Hospital; and ${ }^{\mathrm{b}}$ Department of Cardiothoracic Surgery, Queen Mary Hospital, Hong Kong.

Disclosures: The authors reported no conflicts of interest.

The Journal policy requires editors and reviewers to disclose conflicts of interest and to decline handling or reviewing manuscripts for which they may have a conflict of interest. The editors and reviewers of this article have no conflicts of interest.

Received for publication Sept 4, 2020; revisions received Sept 4, 2020; accepted for publication Sept 8, 2020; available ahead of print Sept 12, 2020.

Address for reprints: Michael K. Y. Hsin, FRCS CTh, Department of Cardiothoracic Surgery, Room 308, New Clinical Building, Queen Mary Hospital, Hong Kong (E-mail: mkhsin@hotmail.com).

J Thorac Cardiovasc Surg 2022;164:581-2

$0022-5223 / \$ 36.00$

Copyright (c) 2020 by The American Association for Thoracic Surgery

http://dx.doi.org/10.1016/j.jtcvs.2020.09.025
}
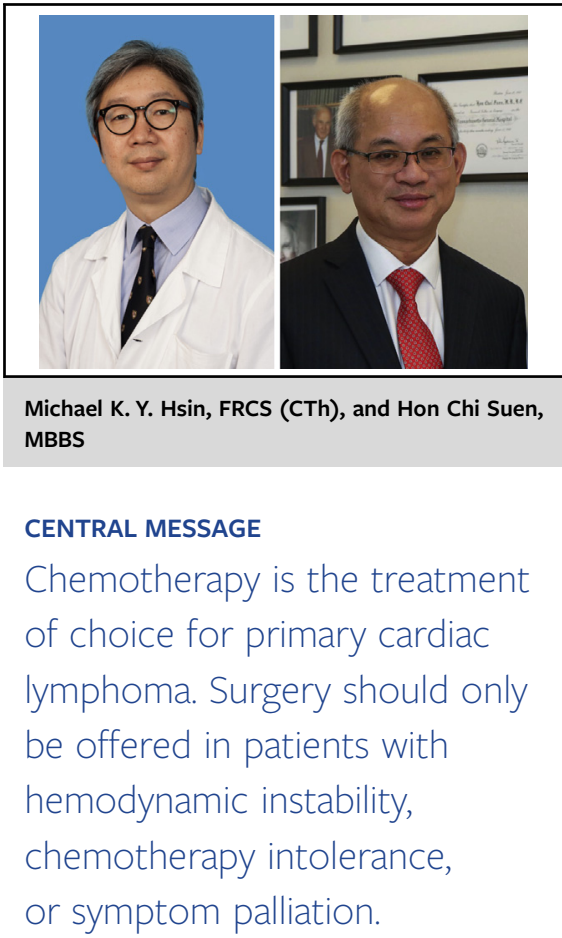

resection for symptoms. This is the largest published series on PCL, and their recommendations serve as good reference guidance for the future management of PCL. Early systemic chemotherapy is the treatment of choice. The SEER database does not provide details on the specific chemotherapy regimen used, and one of the limitations of this study is the evolution in treatment over the long span of the study period. The addition of rituximab to $\mathrm{CHOP}$ has been shown to increase remissions and complete responses in diffuse large B-cell lymphoma, ${ }^{3,4}$ and in PCL the R-CHOP regimen has been shown to improve prognosis. ${ }^{5,6}$

A group from Fujian China recently published a paper that also interrogated the SEER database for PCL over a similar time span. ${ }^{7}$ They also showed that age and chemotherapy were independent prognostic factors for overall survival, but surgery was not. Interestingly, they concluded that chemotherapy combined with surgery was an independent protective factor for overall survival and cause specific survival. However, the Fujian group did not break down the type of surgery involved. It is possible that by including cases of excisional biopsy surgery in their analysis, the Fujian group arrived at a very different conclusion.

Earlier this year, Yin and colleagues ${ }^{8}$ reported on primary cardiac sarcoma using the SEER database. Unlike PCL, both surgery and chemotherapy were found to be independent protective factors in primary cardiac sarcoma, with surgery 
being the strongest. ${ }^{8,9}$ These 2 papers from this group, both based on a large, well-maintained database, provide much needed guidance on the treatment of malignant cardiac tumors and highlight the importance of accurate histological diagnosis before resection.

\section{References}

1. Patel J, Melly L, Sheppard M. Primary cardiac lymphoma: B- and T-cell cases at a specialist UK centre. Ann Oncol. 2010;21:1041-5.

2. Yin K, Brydges H, Lawrence KW, Wei Y, Karlson KJ, McAneny DB, et al. Primary cardiac lymphoma. J Thorac Cardiovasc Surg. 2022;164:573-80.e1.

3. Coiffier B, Lepage E, Brière J, Herbrecht R, Tilly H, Bouabdallah R, et al. CHOP chemotherapy plus rituximab compared with $\mathrm{CHOP}$ alone in elderly patients with diffuse large-B-cell lymphoma. N Engl J Med. 2002;346:235-42.

4. Coiffier B, Thieblemont C, Van Den Neste E, Lepeu G, Plantier I, Castaigne S, et al. Long-term outcome of patients in the LNH-98.5 trial, the first randomized study comparing rituximab-CHOP to standard CHOP chemotherapy in DLBCL patients: a study by the Groupe d'Etudes des Lymphomes de l'Adulte. Blood. 2010;116:2040-5.

5. Miguel CE, Bestetti RB. Primary cardiac lymphoma. Int J Cardiol. 2011;149: 358-63.

6. Bonou M, Kapelios CJ, Marinakos A, Adamopoulos S, Diamantopoulos P, Foukas PG, et al. Diagnosis and treatment complications of primary cardiac lymphoma in an immunocompetent 28-year old man: a case report. BMC Cancer. 2019;19:191.

7. Xiao M, Lin J, Xiao T, Lin Y, Ye Y. The incidence and survival outcomes of patients with primary cardiac lymphoma: a SEER-based analysis. Hematol Oncol. 2020;38:334-43.

8. Yin K, Luo R, Wei Y, Wang F, Zhang Y, Karlson KJ, et al. Survival outcomes in patients with primary cardiac sarcoma in the United States. J Thorac Cardiovasc Surg. January 23, 2020 [Epub ahead of print].

9. Velez A, Lawton J. Commentary: Cardiac sarcoma remains a formidable challenge. J Thorac Cardiovasc Surg. January 22, 2020 [Epub ahead of print].

\title{
Commentary: Don't mess with primary cardiac lymphoma
}

\author{
Matthew C. Henn, MD
}

The advice given to new surgical trainees to eat when you can, sleep when you can, and don't mess with the pancreas was based on the historically limited understanding of pancreatic disease as well as the dismal outcomes when attempting to manage it surgically. Further, the idea was predicated on the relative lack of successful medical management. Surgical management of an even more rare pathological process - primary cardiac lymphoma-is equally poorly understood. The data in the literature are limited to single case reports and small series. However, Yin and colleagues ${ }^{1}$ report on the largest cohort of primary cardiac lymphoma confirms perhaps what we expected from the limited data—don't mess with primary cardiac lymphoma.

From the Division of Cardiac Surgery, Department of Surgery, The Ohio State University Wexner Medical Center, Columbus, Ohio.

Disclosures: The author reported no conflicts of interest.

The Journal policy requires editors and reviewers to disclose conflicts of interest and to decline handling or reviewing manuscripts for which they may have a conflict of interest. The editors and reviewers of this article have no conflicts of interest.

Received for publication Sept 11, 2020; revisions received Sept 11, 2020; accepted for publication Sept 14, 2020; available ahead of print Sept 18, 2020.

Address for reprints: Matthew C. Henn, MD, Division of Cardiac Surgery, Department of Surgery, The Ohio State University Wexner Medical Center, N-825 Doan Hall, 410 West 10th Ave, Columbus, OH 43210 (E-mail: Matthew.henn@ osumc.edu).

J Thorac Cardiovasc Surg 2022;164:582-3

$0022-5223 / \$ 36.00$

Copyright (c) 2020 by The American Association for Thoracic Surgery

http://dx.doi.org/10.1016/j.jtcvs.2020.09.049

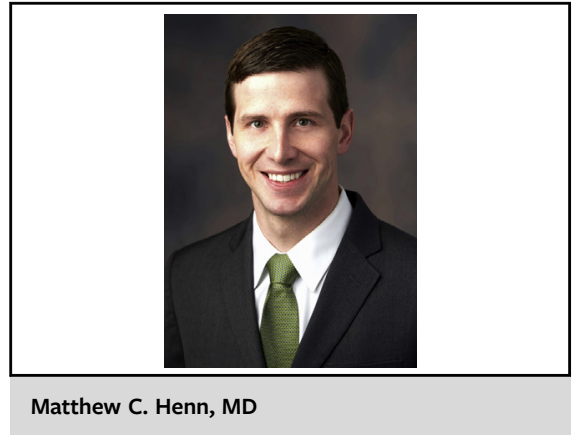

CENTRAL MESSAGE

Primary cardiac lymphoma is a rare disease that is poorly studied, resulting in variation in treatment strategies. However, surgical management, when employed, is unlikely to improve survival.

In the report that includes 184 cases of primary cardiac lymphoma over a 43-year period from the Surveillance, Epidemiology, and End Results Program database only 27 patients underwent any form of surgery, which highlights the reluctance of surgeons to offer resection or debulking. Although the Surveillance, Epidemiology, and End Results Program database lacks granularity of procedural details, the presumption is that surgical management was in the setting of hemodynamic instability, resistance to 